\title{
Equitable Provision of Long-Term Public Goods The Role of Negotiation Mandates
}

\author{
Franck Lecocq, Jean-Charles Hourcade \\ World Bank, Development Research Group \\ Centre International de Recherche sur l'Environnement et le \\ Développement (CNRS, EHESS, ENGREF, ENPC)
}

\begin{abstract}
In a one-period model, whether or not individual weights in the welfare function are based on initial endowments dictate who provides public goods. But with long-term public goods, banning wealth redistribution still allows for several equilibriums depending on Parties' willingness to acknowledge changes in negotiating powers over time, and on whether or not they care only for their own descendants. "Adaptative" and "universal" mandates lead to far more robust equilibrium. In all cases, a simple rule of thumb for allocating expenditures at first period emerges, independent of both the optimal level of public goods and the second-period distribution of expenditures.
\end{abstract}

JEL Classification: D63, H41, Q25

Keywords: Public Goods, Equity, Negotiation, Climate Change

World Bank Policy Research Working Paper 3180, December 2003

The Policy Research Working Paper Series disseminates the findings of work in progress to encourage the exchange of ideas about development issues. An objective of the series is to get the findings out quickly, even if the presentations are less than fully polished. The papers carry the names of the authors and should be cited accordingly. The findings, interpretations, and conclusions expressed in this paper are entirely those of the authors. They do not necessarily represent the view of the World Bank, its Executive Directors, or the countries they represent. Policy Research Working Papers are available online at http://econ.worldbank.org. 


\section{Introduction}

To provide transnational, long-term and uncertain public goods such as biodiversity, a solid ozone layer, or a preserved global climate the international community must confront inter and intra generations distributional issues simultaneously. The economic literature addresses this issue by, inter alia, extending the Bowen-LindhalSamuelson (BLS) conditions to the intergenerational case (Sandler and Smith, 1976).

However, negotiations on transnational and long-term public goods are often uniquely guided by 'ethical intuitions' such as, in the climate change case, the "common but differentiated responsibilities" principle, per capita distribution of emission rights (Agarwal and Narain, 1991), or the grandfathering scheme. On both sides of the Atlantic, players in these negotiations (Bodansky, 2001, Hourcade, 2000) have showed how reluctance to put some economic insights in the discussion have made it difficult to control the political vagaries of the process, let alone find a compromise.

Economists may be partly responsible for their own lack of influence, because of their reflex of keeping ethics separated from economics. This paper builds on the opposite advice, i.e. that "there is something in the methods standardly used in economics, related inter alia with its engineering aspect, that can be of use to modern ethics as well" (A. Sen, 1987, p.9). To do so, using climate as an empirical case, it interprets the benevolent planner metaphor as capturing the behavior of the chairman of a Conference of the Parties ${ }^{1}$ presenting a take or leave proposal in the final hours of the negotiation (Grubb et al., 1999).

Within a two period framework, we define four mandates that can be given to the planner. These mandates combine assumptions about:

- diplomatic attitudes: we distinguish a status-quo approach, whereby current balances of power are used to shape long-term policy, and an adaptative approach whereby evolutions in the

${ }^{1}$ The COP is the negotiating body of the U.N. Framework Convention on Climate Change (UNFCCC). 
distribution of economic income and power are acknowledged and accounted for;

- visions of intergenerational solidarity in the face of climate risks: we distinguish between dynastic solidarity, whereby Parties are concerned by the welfare of their future citizens only, and universal solidarity, whereby Parties consider the welfare of all future individuals, regardless of where they live.

These mandates are analyzed under a no redistribution constraint, because countries are not likely to let climate policies - or any other international treaty of that sort-be the occasion of large-scale wealth redistribution across nations. We first focus on the burden sharing principles which emerge from these mandates, and we question their political viability. We then examine their implications for the level of provision of the public good. At each step, we show the specific role of uncertainty. We conclude with some policy implications, and a discussion of the ethical pre-requisites for regimes aiming at managing long-term public goods in an unequal word.

\section{A Generic Model with Four Alternative Programs}

Let us start from a generic model similar to the one developed by Sandler and Smith (1976). The world is divided in N countries, and there are two periods, present and future, the latter indexed by superscript $\mathrm{f}$. At first period, the representative individual ${ }^{2}$ of the $\mathrm{l}_{\mathrm{i}}$ inhabitants of country $i$ allocates his income $y_{i}$ between $c_{i}$ the consumption of a composite private good chosen as numeraire, and $a_{i}$ his abatement expenses.

$$
\mathrm{y}_{\mathrm{i}}=\mathrm{c}_{\mathrm{i}}+\mathrm{a}_{\mathrm{i}}
$$

Let $x\left(\right.$ resp. $\left.x^{f}\right)$ be the amount of greenhouse gases (GHG) emissions abated worldwide compared to business-as-usual. We use $x+x^{f}$ as an index of GHG concentration in the atmosphere, ${ }^{3}$ and denote $d_{i}\left(x+x^{f}\right)$

\footnotetext{
${ }^{2}$ We will not address the internal distribution of revenue in each country.

${ }^{3}$ This (inversed) index is a simplification of the dynamics of GHG accumulation in the atmosphere, but it suffices in capturing the stock externality character of climate change.
} 
the per capita level of damages incurred in country $i$ at second period at any given level of GHG concentration. Since $x+x^{f}$ aggregates avoided tons of GHG emissions, functions $d_{i}($.$) are decreasing. Thus,$ second period budget equations are as follows.

$$
y_{i}^{f}-d_{i}\left(x+x^{f}\right)=c_{i}^{f}+a_{i}^{f}
$$

We assume that abatement expenses are used efficiently and denote $C(x)$ (resp. $C^{f}\left(x^{f}\right)$ ) the worldwide abatement cost function. The total level of abatement at each period is thus given by:

$$
\sum_{i} 1_{i} a_{i}=C(x) \quad \sum_{i} l_{i}^{f} a_{i}^{f}=C^{f}\left(x^{f}\right)
$$

At the beginning of the first period, the planner/chairman of the COP is charged with proposing an abatement level for each country at both periods. This one-shot model is arguably at odds with the sequential nature of the real climate regime, where targets are set for five-year periods only. But, climate change being a stock externality, the planner cannot but make assumptions about future actions when computing present ones. Second period abatements can thus be interpreted as plans which may, or may not, be carried out.

To come up with a proposal with reasonable chances of being accepted, the planner maximizes a weighted sum of the representative individuals' utilities, and selects weights in function of the mandate he receives from the Parties. If we assume, despite its controversial character from an ethical point of view, ${ }^{5}$ that wealthiest Parties impose a no redistribution constraint, according to which climate policies shall

\footnotetext{
${ }^{4}$ Let $\mathrm{x}_{\mathrm{i}}$ be national abatement levels, and $\mathrm{C}_{\mathrm{i}}\left(\mathrm{x}_{\mathrm{i}}\right)$ the national abatement cost functions. Then $\mathrm{C}(\mathrm{x})=\operatorname{Min}\left\{\sum_{\mathrm{i}} \mathrm{C}_{\mathrm{i}}\left(\mathrm{x}_{\mathrm{i}}\right) \mid \sum_{\mathrm{i}} \mathrm{x}_{\mathrm{i}}=\mathrm{x}\right\}$. This can be interpreted as a carbon fund, provisioned by all countries, which reduces emissions worldwide where it is cheapest to do so.

${ }^{5}$ See e.g. Azar (1999, p.254): "The global welfare function is a normative, not an empirical question, and few would contest that the world would actually be a much better place if the huge differences income were reduced. A situation where the richest billion people live in abundance, and the poorest billion suffer from chronicle hunger, can by no reasonable standards be considered a global welfare maximum."
} 
not be the occasion of large-scale wealth transfer from developed to developing countries, then this collective welfare function must meet the following two conditions.

- national contributions $a_{i}$ and $a_{i}^{f}$ must be non negative, as no Party will accept to abate more in order to endow another Party with emissions rights higher than its baseline prior to any carbon trading. ${ }^{6}$ This condition is seemingly trivial, but we will show that it plays a role in the second period equilibrium.

- Second, the weights attached to representative individuals' utility functions must be such that the initial distribution of wealth $\left(\mathrm{y}_{\mathrm{i}}\right)$ is welfare maximizing. ${ }^{7}$ Negishi (1960) tells us that these weights are unique - up to a scale factor - and equal to the inverse of the marginal utility of initial income. If utility functions are logarithmic and if first and second period consumption are separable, these weights are proportional to per capita income. ${ }^{8}$

However, the set of welfare functions which meet these restrictions is still rather large because there are various ways of interpreting the no redistribution imperative at second period, and various attitudes vis-à-vis climate damages.

With regard to the no redistribution constraint, modelers (e.g., Nordhaus and Yang, 1996) often consider that it applies separately at each period. The Negishi weights are thus made time varying so that the projected distribution of income $\left(\mathrm{y}_{\mathrm{i}}^{\mathrm{f}}\right)$ is also welfare maximizing at second period. But, by doing so, one makes a strong assumption about the political economy of the negotiation, namely that Parties agree to ask the planner to anticipate changes in income distribution. In other

\footnotetext{
${ }^{6}$ The excess quota allocated to Russia and Ukraine by the Kyoto Protocol is obviously a pure tactical concession. A milder approach to this first constraint is that no Party shall benefit from climate policy as a whole; thus the sum of contribution and damages shall be non negative $\left(a_{i}^{f}+d_{i}^{f}>0\right)$.

${ }^{7}$ To avoid any misunderstanding, let us make clear that this technical trick capturing political constraints does not imply a substantive value judgment on the equity of the current state of the World.

${ }^{8}$ Were these weights all set to 1 , total wealth should be redistributed so as to achieve equal per capita income.
} 
words, this presupposes a consensus on the legitimacy-or the ineluctability - of changes in economic balances, which contradicts diplomatic traditions where negotiating positions are governed by prevailing balances of power.

It is not implausible that Machiavelli's qualification of States as "cold monsters" will remain valid in the 21st century. The richest countries may well not accept the ineluctable decline of their share in world's wealth, or may at least tend to use their current superiority to slow down this decline. They may then be tempted by a status-quo mandate, in which they force the planner to calibrate the collective welfare function at both periods based on current income distribution.

Regarding the interplay between the assessment of climate damages and intergenerational equity, two polar attitudes are again possible. The first derives from the observation that negotiating teams, defending national interests, and speaking on behalf of both their present and unborn fellow citizens, tend to follow a dynastic solidarity conduct and primarily consider the damages falling on their own country. A polar option, supported by many NGOs, is that decisionmakers should adopt a universal solidarity ethics, and should be concerned by the welfare of all future individuals, regardless of where they live, and regardless of where damages fall. ${ }^{9}$ These alternatives can be translated analytically by making second period utilities dependent, or not, on damages in other countries.

\footnotetext{
${ }^{9}$ We will discuss later the ethical rationale and political likelihood of this mandate. For the time being, we treat it as a pure logical possibility.
} 
Four possible programs can be derived by combining these two sets of hypothesis. If we denote $U_{i}\left(\right.$ resp. $\left.U_{i}^{f}\right)$ the representative individuals' utility functions, $\alpha_{\mathrm{i}}$ and $\beta_{\mathrm{i}}$ the first and second period weights attached to these functions, and $\varphi$ the utility discount factor, ${ }^{10}$ they are:

- "Dynastic solidarity" and "status-quo" mandate:

$$
\begin{array}{ll}
W=\sum_{i} l_{i} \alpha_{i} U_{i}\left(c_{i}\right)+\varphi \sum_{i} l_{i}^{f} \alpha_{i} U_{i}^{f}\left(c_{i}^{f}\right) & \\
\alpha_{i}=\frac{\alpha}{U_{i}^{\prime}\left(y_{i}\right)} & \text { with } \alpha=\left(\sum_{i} \frac{l_{i}}{U_{i}^{\prime}\left(y_{i}\right)}\right)^{-1}
\end{array}
$$

- "Dynastic solidarity" and "anticipative" mandate:

$$
\begin{array}{ll}
W=\sum_{i} 1_{i} \alpha_{i} U_{i}\left(c_{i}\right)+\varphi \sum_{i} 1_{i}^{f} \beta_{i} U_{i}^{f}\left(c_{i}^{f}\right) & \\
\alpha_{i}=\frac{\alpha}{U_{i}^{\prime}\left(y_{i}\right)} & \text { with } \alpha=\left(\sum_{i} \frac{l_{i}}{U_{i}^{\prime}\left(y_{i}\right)}\right)^{-1} \\
\beta_{i}=\frac{\beta}{U_{i}^{f \prime}\left(y_{i}^{f}\right)} & \text { with } \beta=\left(\sum_{i} \frac{1_{i}^{f}}{U_{i}^{f}\left(y_{i}^{f}\right)}\right)^{-1}
\end{array}
$$

- In "Universal solidarity" mandates, damages falling on other countries should enter into the computation of the utility of the representative individual of country $i$, in addition to those falling directly on the country i. "Universal solidarity" and "status-quo" or "dynastic" mandates are thus obtained by substituting $\mathrm{U}_{\mathrm{i}}^{\mathrm{f}}\left(\mathrm{c}_{\mathrm{i}}^{\mathrm{f}}, \mathrm{d}_{1}^{\mathrm{f}}, \ldots, \mathrm{d}_{\mathrm{i}-1}^{\mathrm{f}}, \mathrm{d}_{\mathrm{i}+1}^{\mathrm{f}}, \ldots, \mathrm{d}_{\mathrm{N}}^{\mathrm{f}}\right)$ to $\mathrm{U}_{\mathrm{i}}^{\mathrm{f}}\left(\mathrm{c}_{\mathrm{i}}^{\mathrm{f}}\right)$ in equations (4) and (6) respectively.

\footnotetext{
${ }^{10}$ We make the following technical assumptions. First, present and future consumptions are assumed separable. Second, individual utility functions are all twice differentiable, with $U^{\prime}>0$ and $U^{\prime \prime}<0$. Third, the sum of weights over all individuals in all country is equal to one, i.e. that $\sum_{i} 1_{i} \alpha_{i}=1$, and $\sum_{i} 1_{i} \beta_{i}=1$. Fourth, all Parties have the same pure time preference. This still allows for differentiated discount rates across countries, as utility functions and growth rates might differ.
} 


\section{Burden Sharing at First Period: Towards an Easy Rule of Thumb?}

In all four mandates, solving the planner's program yields the same result at first period: abatement expenses should be allocated so as to equate after abatement weighted marginal utilities of consumption across countries (see Appendix 1 for full derivation of this result, which expresses the BLS condition in the context of our model).

$$
\alpha_{1} U_{1}^{\prime}\left(y_{1}-a_{1}\right)=\ldots=\alpha_{N} U_{N}^{\prime}\left(y_{N}-a_{N}\right)
$$

Since by virtue of the no redistribution constraint, before abatement weighted marginal utilities are also equal, the optimal distribution of abatement costs decreases weighted marginal utilities by the same amount.

$$
\alpha_{1} \mathrm{U}_{1}^{\prime}\left(\mathrm{y}_{1}\right)-\alpha_{1} \mathrm{U}_{1}^{\prime}\left(\mathrm{y}_{1}-\mathrm{a}_{1}\right)=\ldots=\alpha_{\mathrm{N}} \mathrm{U}_{\mathrm{N}}^{\prime}\left(\mathrm{y}_{\mathrm{N}}\right)-\alpha_{\mathrm{N}} \mathrm{U}_{\mathrm{N}}^{\prime}\left(\mathrm{y}_{\mathrm{N}}-\mathrm{a}_{\mathrm{N}}\right)
$$

Figure 1 provides a geometric illustration of this result, picturing two regions differing only in income. Since preferences are the same, the poor region has a higher marginal utility of consumption (B) than the rich one (A). To comply with the no redistribution constraint, the planner chooses $\alpha_{\text {poor }}$ (normalizing $\alpha_{\text {rich }}$ to 1 ) so that the weighted marginal utilities of consumption in both regions are equal. The weighted marginal utility of the poor region is thus $C$ instead of $B$. To preserve this equality in the post abatement equilibrium, it suffices to find the horizontal line intersecting with both the marginal utility function of the rich (continuous line) and the weighted marginal utility function of the poor (dotted line), such that $a_{\text {poor }}+a_{\text {rich }}$ is equal to the total desired level of abatement.

How do contributions $\mathrm{a}_{\text {rich }}$ and $\mathrm{a}_{\text {poor }}$ compare? Geometrically, $\mathrm{a}_{\text {poor }}$ is lower than $a_{\text {rich }}$ if the slope of the weighted marginal utility function is steeper at point $C$ than the slope of the marginal utility function is at point A. An analytic condition can be derived when contributions are all assumed to remain small compared with initial revenues. In that case, equation (10) can be approximated by: 


$$
-\frac{U^{\prime \prime}}{U^{\prime}}\left(y_{\text {poor }}\right) a_{\text {poor }} \approx-\frac{U^{\prime \prime}}{U^{\prime}}\left(y_{\text {rich }}\right) a_{\text {rich }}
$$

And $\mathrm{a}_{\text {poor }}$ is lower than arich if and only if

$$
-\frac{U^{\prime \prime}}{U^{\prime}}\left(y_{\text {poor }}\right)>-\frac{U^{\prime \prime}}{U^{\prime}}\left(y_{\text {rich }}\right)
$$

The latter condition holds (see Appendix 2) for any $\mathrm{y}_{\text {poor }}<\mathrm{y}_{\text {rich }}$ in a large class of utility functions, including inter alia logarithmic $\mathrm{U}=\ln (\mathrm{c})$ and exponential $\mathrm{U}=\mathrm{c}^{\mathrm{a}}(0<\mathrm{a}<1) .{ }^{11}$ With such functions, optimal abatement expenditures are even proportional to per capita revenues: if the average European is 46 times richer than the average Indian, ${ }^{12}$ then each European should contribute 46 times more to climate mitigation, in absolute terms, than the average Indian. However, by construction of the weights, their utility loss is identical.

This has four policy implications for the first period. First, all countries should contribute to climate mitigation. Second contributions are in general progressive with, and proportional to, income. Third, this burden sharing rule-at least as long as contributions remain small with regard to initial revenues-is independent from both the global level of public goods $x+x^{f}$, and from the first period abatement level $x$. Last, it is entirely independent from the distribution of the impacts of climate change, and thus robust to their uncertainty (see Appendix 3) since it depends only on firstperiod utilities and income levels.

In sum, regardless of the mandate, intra-generational equity at first period can be addressed using a simple "rule of thumb" based on observable parameters and can be separated from the controversies about intergenerational distribution of abatement costs, and about the geographical distribution of climate change damages.

\footnotetext{
${ }^{11}$ Since in both cases $-\frac{\mathrm{U}^{\prime \prime}}{\mathrm{U}^{\prime}}=\frac{1}{\mathrm{c}}$.

12 Based on 2000 Gross National Income, as reported in World Bank, 2002.
} 


\section{Burden Sharing at the Second Period: when Mandate Matters}

We now turn on to burden sharing at second period. This section is mostly analytical. However, numerical exercises with two regions, "North" and "South", will help figure out the orders of magnitude at stake, and grasp the economic and ethical interpretation of our findings (see Appendix 4 for details of the calibration).

\subsection{The Status-Quo - Dynastic Mandate at Risk of Instability}

Under the status-quo - dynastic mandate, burden sharing at second period is governed, like in the first, by the equalization of weighted marginal utilities of consumption:

$$
\alpha_{1} U_{1}^{f^{\prime}}\left(y_{1}^{f}-d_{1}^{f}\left(x+x^{f}\right)-a_{1}^{f}\right)=\ldots=\alpha_{N} U_{N}^{f \prime}\left(y_{N}^{f}-d_{N}^{f}\left(x+x^{f}\right)-a_{N}^{f}\right)
$$

The resulting distribution of abatement costs, however, is dramatically different. This is in part due to the fact that both damages and abatement expenses enter in (13). But the main reason is that, since weights $\alpha_{i}$ are calibrated on first period income levels $y_{i}$, the vector $\mathrm{y}_{\mathrm{i}}^{\mathrm{f}}$ has no reason to be welfare maximizing. In most instances, in fact, it is not.

Figure 2 shows what happens in this case (assuming that damages remain small compared to second period revenues), again for two regions differing only by income. If before abatement weighted marginal utilities differ, then the optimal plan consists in charging all abatement expenditures to the country with the lowest weighted marginal utility. The planner shall do so until abatement costs raise the weighted marginal utility of that particular country enough to equate the level of the second in rank, at which point both are charged; and so on until all abatement expenditures are allocated.

If all present and future individuals have the same utility function, then the country with the highest growth rate in the first period is usually the one with the lowest weighted marginal utility at second period, regardless of how rich or poor it is relative to others (see 
Appendix 5 for a demonstration). Since developing countries are consistently projected to experience higher growth rates than developed economies in the coming decades (e.g., Naki enovi and Swart, 2000, World Bank, 2003), this leads to the paradoxical outcome that they be asked to finance most or all the climate mitigation policy. Let us assume, for example, that the developing world grows by $3 \%$ annually over the next decade, while rich countries grow by only $2.5 \%$. In this scenario, the developing world would be about $5 \%$ richer in 2010 than it would have been with a $2.5 \%$ growth rate. This "extra growth" represents about $1 \%$ of the world gross product in 2010 . In the "status-quo dynastic" mandate, all the effort should therefore fall on the developing world as long as the annualized abatement costs do not exceed that - very large-amount.

This result cannot be reversed when accounting for climate damages, even though they are expected to be higher in the developing world (McCarthy et al., 2001). If we assume-fairly conservatively - that per capita GDP growth in the developing world is half a point higher than in developed countries during the next 50 years, then per capita GDP in 2050 is $27 \%$ higher in the developing world than it would have been had both rates been equal. Regional damages apt to rip off this "overgrowth" are beyond the most pessimistic expectations, small Island-States and Sub Saharan Africa excepted.

In sum, under this mandate, large countries such as China, India, Brazil, or Mexico would be called to pay most of the abatement expenditures at second period, even if they suffer from higher damages than the developed world. Factoring uncertainty in complicates the problem but does not change its structure (see Appendix 3).

This result looks so unacceptable from an ethical point of view that one cannot but question the policy relevance of the underlying model. In particular, and even though numerical experiments demonstrate that the issue does not vanishes with shorter time periods, one could argue that in real world decision-making process, Parties agree only 
on first period expenses, and that the second period distribution plan can always be renegotiated.

This is true. Yet, the model developed in section 2 captures the outcome of a situation where the first period decision has long-term impacts. And examples abound of long-lasting arrangements built on relative bargaining powers which have dramatically changed since then. The composition of the U.N. Security Council, or the voting system in the U.S. are two outstanding examples. In the climate policy context, limits to renegotiating allocation rules come from the very cornerstone of the Kyoto regime, that is an international carbon trading system. Its dynamic efficiency would indeed be undermined by the absence of predefined rules which help governments and private agents form expectations over the future carbon prices. Changing rules too drastically, or too often, might lead agents to refrain from using emissions trading (OECD, 1993).

Moreover, the rationale of the status-quo - dynastic mandate is to expand the grandfathering principle to future generations. Indirectly, equation (13) comes to endowing the future inhabitants of the rich countries with emissions rights in part based on those acquired by their predecessors. Viewed in that light, the no redistribution constraint comes to repeated grandfathering; it is consistent with the claim that "the U.S. lifestyle is not negotiable."13

At first period, grandfathering is legitimated by the fact that vested interests need to be compensated for the modification of the social contract from a situation without to a situation with carbon constraint. But this argument does not hold over the long-run, and the rejection of any form of grandfathering explains the repeated warning by the G77 and China that "there would be no agreement on carbon trading until the question of emissions rights and entitlements is addressed equitably. "14

\footnotetext{
${ }^{13}$ Even though this is a quote from a former U.S. President, it is fair to note that it would probably be endorsed in many quarters of the developed world.

${ }^{14}$ UNFCCC document SB/1998/MISC.1/Add.3/Rev.1 Preparatory work for the fourth session of the Conference of the Parties on the items listed in decision 1/CP.3, paragraph 5, Indonesia (on behalf of the Group of 77 and China).
} 
In sum, under the "status-quo dynastic" mandate, two main outcomes are possible: either the Chairman's proposal is immediately rejected by the poor countries, or it is accepted at first period, but generates tensions at the second and strong incentives to defect.

\subsection{Winners-Losers Dilemma in the Adaptative - Dynastic Mandate}

Under an adaptative - dynastic mandate, burden sharing at second period is again governed by the equalization of weighted marginal abatement utilities.

$$
\beta_{1} U_{1}^{f \prime}\left(y_{1}^{f}-d_{1}^{f}\left(x+x^{f}\right)-a_{1}^{f}\right)=\ldots=\beta_{N} U_{N}^{f \prime}\left(y_{N}^{f}-d_{N}^{f}\left(x+x^{f}\right)-a_{N}^{f}\right)
$$

Since weights i reflect the business-as-usual distribution of wealth at second period, the results of section 3 apply. But they now apply to the sum of abatement expenditures and damages. It is thus the total climate change bills that should be allocated progressively with, and often in proportion to, per capita income. In other words, abatement expenditures depend not only on the before abatement distribution of wealth, but also on the distribution of the residual damages of climate change.

A numerical example will illustrate how this changes the results. Let us assume that developed $(\mathrm{N})$ and developing regions $(\mathrm{S})$ share the same logarithmic utility function. Their first period per capita revenue differ by a factor 23 . Higher per capita GDP growth in $S$ from first to second period ( $3 \%$ vs. $2.5 \%$ ) reduces this range from 1 to 18 in 2050 . But at that time, population of $S$ has increased by $40 \%$ while population of $\mathrm{N}$ has remained constant. Damages in both regions are assumed quadratic in $x+x^{f}$, but we test several assumptions about their magnitude (see Appendix 4 for details on the calibration). The results are summarized in Table 1.

In scenario a, climate change results in the same share of income loss in $\mathrm{N}$ and $\mathrm{S}$ (5\% at maximum, i.e. without any abatement). In that case, optimal abatement expenditures are also allocated proportionally to per capita income, and thus so are the total climate bills. In scenario 
b, at any given level of GHG concentration, damages rip off a higher share of per capita income in $\mathrm{S}$ than in $\mathrm{N} \mathrm{(6 \%} \mathrm{vs.} 4 \%$ at maximum). $\mathrm{N}$ is then demanded to devote a higher share of its income to abatement so that the total climate bills can represent the same share of revenues in both regions $(2.15 \%)$. In scenario c, the differential widens ( $7 \%$ vs. $3 \%)$, and S is so impacted that it should essentially not pay anything for abatement. Yet climate bills are still equal. In scenario d however, damages are so high in $\mathrm{S}$, that even with zero abatement expenditures, $\mathrm{S}$ still support a higher climate bill than N $(2.47 \%$ vs. $1.70 \%$ of per capita revenue). In the latter case, the no redistribution constraint $\mathrm{a}_{\text {north }}^{\mathrm{f}} \geq 0$ is binding.

The latter situation, which is far from implausible for Sub-Saharan Africa or small Island-States, puts the no redistribution constraint to a serious test. Direct compensations for the extra damages excess can only be paid if Parties adopt a more lenient interpretation of it, for example if they consider that it applies to the sum of damages and abatement expenditures (i.e., $a_{i}^{f}+d_{i}^{f} \geq 0$ ).

But the main difficulty of this mandate stems from the very fact that damages will remain difficult to observe, quantify and compare across countries. Projections of average increases in temperature by global circulation models have indeed a higher degree of confidence than projections at a local scale, and uncertainty grows by orders of magnitude when translating local physical impacts into economic damages (McCarthy et al., 2001). For example, Western Europe may experience either a $2^{\circ} \mathrm{C}$ warming or a several degrees cooling depending on the evolution of the North-Atlantic thermohaline circulation. Similarly, Russia can be counted amongst the winners of global warming, unless the melting of the permafrost, or difficulties for vegetation to adapt to warming, prove dramatic.

Table 1 shows that even small divergences in climate damages expectations can significantly alter the allocation of abatement expenditures. The proposed deal is thus at risk of not being accepted-as all Parties are interested in inflating their estimates in order to minimize their contribution to abatement expenditures and 
increase their - , or at risk of being seriously undermined should the gap between expected and realized damages require important amendments to the initial agreement.

\subsection{Universal Solidarity Mandates: More Robust to Uncertainty?}

The "dynastic solidarity" mandates are based on the premise that Parties are primarily interested in the fate of their own descendants. This premise seems consistent with dominant diplomatic conducts.

However, alternative "universal solidarity" mandate-in which Parties consider all damages wherever they fall - can also be justified; even without resorting to a universal bonhomie attitude. A first argument stems from Schelling's suggestion (1995) that, beyond some horizon, all individuals are indistinct. ${ }^{15}$ A second derives from pure self interest: faced with tremendous uncertainties regarding the regional distribution of climate damages and related economic consequences, Parties might refrain from indulging themselves in the camp of the winners. ${ }^{16}$ In addition, given the risks of propagation of local shocks, such as increased economical and political instability or accelerated migration, ${ }^{17}$ Parties might consider that any important impact anywhere will propagate and ultimately affect everyone's welfare and security. ${ }^{18}$

A status-quo - universal solidarity mandate thus makes sense. The status-quo component of the mandate relates to a selfish attitude which does not contradict the universal solidarity component, at least under the well understood self-interest motivation. But in terms of allocation of abatement costs, this mandate confronts the same difficulty as the status-quo dynastic mandate: precisely, the fact that

\footnotetext{
${ }^{15}$ The same intuition underlies the proposal of an hyperbolic discount rate.

${ }^{16}$ A situation analogous to the "veil of ignorance" described by John Rawls (1971).

${ }^{17}$ This is all the more important since adverse climate impacts may fall disproportionally on fragile regions in developing countries.

${ }^{18}$ The concept of solidarity can thus be understood in its etymological sense: solidus: compact and hence 'solid': with whom we consider to be bound either for reasons of benevolence or because our interests stick together.
} 
damages are now universally accounted for does not solve the secondperiod allocation problem, as growth differentials still exist.

In an adaptative - universal solidarity mandate, the distribution of contributions at both periods is governed by the same principle as in the adaptative - dynastic solidarity case. The main difference concerns the treatment of damages. A low impacted country will indeed account, at least in part, for damages falling on other countries. This has two consequences. First, the total level of damages considered by Parties increases compared to the dynastic case because, on top of national damages, damages abroad also matter. We develop that point in the next section. Second, the uncertainty on the distribution of damages - at constant global impact-plays a lesser role. If damages expected on $\mathrm{S}$ ultimately fall on $\mathrm{N}$ the error is compensated by the fact that part of them were already accounted in the utility function of $\mathrm{N}$. Uncertainty at local level is a weaker obstacle to agreement.

\section{Levels of Abatement}

We now turn on to the consequences of the four mandates on the provision of public goods. The optimal abatement levels are given by equations (15) and (16) below. In both equations, the first terms are common to all mandates, while the second are specific to the universal solidarity mandates.

$$
\begin{gathered}
C^{\prime}(x)=-\varphi \sum_{i} 1_{i}^{f} \omega_{i} \frac{U_{i}^{f \prime}\left(y_{i}^{f}-a_{i}^{f}-d_{i}\left(x+x^{f}\right)\right)}{U_{i}^{\prime}\left(y_{i}-a_{i}\right)} d_{i}^{\prime}\left(x+x^{f}\right) \\
-\varphi \sum_{i} 1_{i}^{f} \omega_{i} \sum_{j \neq i} \frac{\partial U_{i}^{f} / \partial d_{j}^{f}}{U_{i}^{f}\left(y_{i}^{f}-a_{i}^{f}-d_{i}^{f}\right)} d_{j}^{\prime}\left(x+x^{f}\right) \\
C^{f^{\prime}}\left(x^{f}\right)=-\sum_{i} 1_{i}^{f} \pi_{i} d_{i}^{\prime}\left(x+x^{f}\right)-\sum_{i} 1_{i}^{f} \pi_{i} \sum_{j \neq i} \frac{\partial U_{i}^{f} / \partial d_{j}}{U_{i}^{f \prime}\left(y_{i}^{f}-a_{i}^{f}-d_{i}^{f}\right)} d_{j}^{\prime}\left(x+x^{f}\right)
\end{gathered}
$$

Coefficients $\omega_{i}$ are ratios between second period and first period weights for individual representatives. They are thus equal to 1 in "dynastic" mandates, and to $\beta_{\mathrm{i}} / \alpha_{\mathrm{i}}$ in "adaptative" mandates. 
Coefficients $\pi_{\mathrm{i}}$ have a slightly different signification: they are ratios between the weighted marginal utility of consumption and the shadow price of abatement at second period. When a country contributes to abatement expenses at second period-i.e. when its contribution $\mathrm{a}_{\mathrm{i}}^{\mathrm{f}}$ are strictly positive-its coefficient $\pi_{\mathrm{i}}$ is thus equal to 1 . But if it does not contribute to abatement expenses - either because it's growth rate is too small in "status-quo" mandates, or because it suffers damages which are too high in "adaptative" mandates-its coefficient $\pi_{\mathrm{i}}$ becomes higher than 1 .

These definitions being introduced, let us now interpret (15) and (16). First, these equations establish that the public good should be provided up to the point where its marginal cost of production matches the sum of marginal utilities of consumption of the public goods of all parties involved. This is identical to the BLS condition in the one period model, with the only difference that, at first period, the marginal utility of public good consumption tomorrow has to be compared with the marginal utility of private good consumption today.

This results, however, translates differently depending on the mandate. It is convenient to start with the adaptative case $\left(\omega_{i}=\beta_{i} / \alpha_{i}\right)$, in its dynastic form (the second term drops in both equations), and to assume a situation where all countries contribute at second period (all $\pi_{\mathrm{i}}=1$ ). In that case, (15) and (16) can be simplified in (17) and (18) below, where $\rho$ is the "average" consumption discount factor associated with the utility discount factor $\varphi$, the growth rate assumptions and the shape of the utility functions. ${ }^{19}$

$$
\begin{aligned}
& C^{\prime}(x)=-\rho \sum_{i} 1_{i}^{f} d_{i}^{\prime}\left(x+x^{f}\right) \\
& C^{f^{\prime}}\left(x^{f}\right)=-\sum_{i} 1_{i}^{f} d_{i}^{\prime}\left(x+x^{f}\right)
\end{aligned}
$$

\footnotetext{
${ }^{19}$ See Appendix 1 for detailed expression of $\rho$.
} 
The key result is that the only determinant of the level of effort in this case is the world-aggregate marginal damage function $\sum_{i} 1_{i}^{f} d_{i}^{\prime}($.$) .$ Weights $\alpha_{\mathrm{i}}$ or $\beta_{\mathrm{i}}$ do not play a role in setting the absolute level of action (although they are critical for the distribution of expenses, as we've seen above).

This standard BLS result has critical policy consequences. It confirms indeed that the debates on absolute level of action and on the distribution of abatement expenditures can be separated at first period. Relatedly, the optimal level of provision of public goods does not depend on the distribution of damages, but only on the world aggregate damage function.

Does this property remain valid when some countries do not contribute (and their $\pi_{\mathrm{i}}$ are greater than unity)? Analytically, the answer is no, as the planner puts a premium on the countries damages, and therefore raises the optimal level of action. Numerical simulations, however, suggest this change remains modest. Table 2 displays the results of simulations where, for a given world aggregate marginal damage function, an increasingly large share of those falls on $\mathrm{S}$. But even in the extreme case (scenario $\mathrm{j}$ ) where all damages fall on $S$, against none on $\mathrm{N}$, the optimal emission level is down by less than $0.7 \%$ compared with the case where both $\mathrm{N}$ and $\mathrm{S}$ could see $5 \%$ of their revenues impacted (scenarioa). This intuition behind these figures is that, although the gap between damages in $\mathrm{S}$ and $\mathrm{N}$ is very large, the gap between the weighted marginal utility of $S$ and the shadow price of carbon, which drives the value of weight $\pi_{\mathrm{S}}$, is smaller.

Compared with this mandate, the status-quo dynastic case, leads to a higher total abatement; first period abatement remains virtually unchanged, but second-period abatement rises, as is illustrated in Table 3 . This is again due to weights $\pi_{\mathrm{i}}$, which are equal to one in the countries which end up paying all the abatement expenditures (developing countries), but greater than unity in the others. This raises the total abatement at second period. First-period abatement, on the 
other hand, remains virtually unchanged because the implicit discount rate between periods retained by the planner rises with the "overgrowth" of some countries compared with the others. Keeping the same assumptions as in the paragraph above, the optimal abatement over the two periods, in this mandate, is 30\% against $28 \%$ in the adaptative dynastic case. First period abatement decreases by $1 \%$ (from $6 \%$ to $5 \%$ ) while second period abatement increases from $45 \%$ to $48 \%$.

How do these abatement levels compare with the universal mandates? In the adaptative - universal mandate, the volume of abatement rises significantly. As shown in equations (15) and (16), for each level of concentration, and everything else equal, the total value of damages in the planner's program is higher by virtue of the crosscountry impacts. ${ }^{20}$ The extent to which abatement levels increase, however, rests entirely on the specifications of the second-period utilities and how they capture the cross-country impacts.

Let us assume for example that damages are such that they could wipe up to $2 \%$ of the baseline income in region $\mathrm{N}$, against $5 \%$ in $\mathrm{S}$, and let us compare the adaptative-dynastic case-where all utilities are logarithmic in local consumption - to the adaptative-universal case where second-period utilities are multiplied by a factor which depends on total damages. Let us assume, fairly conservatively, that this factor is unity when damages are zero, and increases linearly with total damages, to culminate at 0.99 (a $1 \%$ loss of utility) when damages are maximal. In the dynastic case, the abatement level-on average across both periods - is $28 \%$; it climbs to $34 \%$ in the universal case.

\footnotetext{
${ }^{20}$ We do not consider the possibility here that some countries may benefit from climate change impacts in others.
} 


\section{Conclusion}

The IPCC statement that "for the purposes of analysis, it is possible to separate efficiency from equity [in the analysis of climate mitigation policies]" (Bruce et al., 1996, p.6) is grounded in the second theorem of welfare. But it also translates professional economists' fear of the regressum ad infinitum of ethical controversies that any debate over burden sharing might trigger (Hourcade, 1994). Ritualistic arguments opposing "realists" and "utopians" over the current distribution of wealth, or over the "right" value of the discount rate, indeed seem to offer little hope for compromise; and economists cautiously defer them to a hypothetical policy decision..$^{21}$

Yet, this position is difficult to hold, for two main reasons. The first is theoretical: the validity of the second theorem of welfare for environmental public goods is questioned. Chichilnisky et al. (2000), for example, show that it does not hold for a privately produced public good, since of all the possible ways of distributing a given amount of emissions rights, few are compatible with efficient markets. 22

The second argument is more pragmatic. Debates over the postKyoto climate regime, among others, demonstrate that equity arguments cannot be brushed aside for later discussion. They constitute, in fact, the core of the debate, and they are likely to have a critical influence on the nature of the agreement, efficiency included, since efficiency depends strongly on the size of the coordination (Toth et $a$ l., 2001).

This paper thus revisits the non-orthogonality between equity and efficiency, but in a wider context of ethical issues. Even within a conservative no redistribution constraint, and under a given pure time preference, it shows how dealing with long-term public goods-

${ }^{21}$ Or, at the IPCC puts it, to "effective institutions for appropriate redistribution of climate change costs," which amounts to the same (Bruce et al., 1996, p.7).

${ }^{22}$ Although Chao and Peck (2000) responded that this point was numerically of second order in the case of climate change. 
roughly captured here in a two-period model-raises two critical questions with high ethical underpinning:

- Diplomatic attitudes: should Parties stick or not to the reflex of using current balances of power to shape future agreements (status-quo vs. adaptative mandates)?

- Attitudes vis-à-vis future generations: should Parties consider only their own descendants, or all future individuals when uncertain risks are at stake (dynastic versus universal)?

With regard to the first parameter, status quo mandates lead to the paradoxical outcome of charging countries with the highest growth rate at second period. Consequently, either developing countries reject this outcome, or the agreement is likely to prove very unstable over time. Adaptative mandates circumvent this trap and allow at both periods, in general, for a burden allocation progressive with income.

But this rule - which is valid at first period in all mandates - applies at second period to the sum of expenditures and climate damages. This complicates the matter. First, some countries might be so impacted that they should not contribute to climate mitigation at all, or should even be compensated, which puts the no redistribution constraint to a serious test. Second, the controversy over who wins and who loses from climate change is likely to block any agreement in a context of large uncertainties over regional climate predictions.

These controversies can be calmed down somewhat if Parties adopt a universal solidarity attitude - be it out of benevolence, for fear of the propagation of local shocks, or out of limited confidence in countrylevel damage projections. The optimal provision of public goods is higher, since cross-country impacts are now accounted for. Interestingly, we show that this ethical parameter is numerically far more significant for the optimal provision of public goods than the weights $\alpha_{i}$ which have attracted so far most of the attention (for example in the discussion between Chichilnisky et al. and Chao and Peck). Ultimately, for given sets of beliefs regarding climate change, uncertainty over its distribution matters less and the agreement is easier to reach. 
This analysis has two main policy implications. First, it shows that, even within a conservative no redistribution constraint, the optimal allocation of the costs of producing the public good follows a simple 'rule of thumb', in general proportionality to per capita revenue. This outcome might be consistent with the "common but differentiated responsibilities" principle of the UNFCCC. But, and this is a strong assumption, this presupposes that Parties to follow a "universal solidarity" attitude, and that the wealthiest ones to refrain from using their negotiating power to shape future agreement as well as current one, for example through institutional lock-ins.

Second, this burden sharing rule, at first period at least, proves independent from both the global level of effort and from the geographical distribution of damages. This is of important for the debate over the immediate post-Kyoto regime, where damages are still expected to remain small. In the longer run though, the distribution of efforts and the distribution of damages cannot be separated anymore. Universal approaches simply reduce the risk that the ex post distribution of damages be very different from the ex ante evaluation. Independence from the overall effort though, is preserved.

To conclude, let us recognize that this analysis suffers from a number of limitations, in particular because it only considers moves along a Pareto frontier: neither the impact of income distribution on the production frontier (Guesnerie, 1995) nor no-regret measures (Hourcade et al., 1996) are considered. Despite these limitations however, it hopefully helps re-ranking the ethical debates about the long term provision of uncertain public goods and it provides a benchmark to assess the equitable character of the various formulae, based on observable variables, which can be proposed to determine future commitments within international regimes (e.g., Lecocq and Crassous, 2003). 


\section{Appendix 1: Model Resolution under Certainty}

Assuming certainty, the most general version of the planner's problem is:

$\operatorname{Max} \sum_{i} \mathrm{l}_{i} \alpha_{i} \mathrm{U}_{\mathrm{i}}\left(\mathrm{y}_{\mathrm{i}}-\mathrm{a}_{\mathrm{i}}\right)+\varphi \sum_{\mathrm{i}} \mathrm{l}_{\mathrm{i}}^{\mathrm{f}} \chi_{\mathrm{i}} \mathrm{U}_{\mathrm{i}}^{\mathrm{f}}\left(\mathrm{y}_{\mathrm{i}}^{\mathrm{f}}-\mathrm{a}_{\mathrm{i}}^{\mathrm{f}}-\mathrm{d}_{\mathrm{i}}\left(\mathrm{x}+\mathrm{x}^{\mathrm{f}}\right), \mathrm{d}_{1}^{\mathrm{f}}, \ldots, \mathrm{d}_{\mathrm{i}-1}^{\mathrm{f}}, \mathrm{d}_{\mathrm{i}+1}^{\mathrm{f}}, \ldots, \mathrm{d}_{\mathrm{N}}^{\mathrm{f}}\right)$

Under the following constraints:

$$
\begin{aligned}
& \sum_{i} l_{i} a_{i}=C(x) \\
& \sum_{i} l_{i}^{f} a_{i}^{f}=C^{f}\left(x^{f}\right) \\
& a_{i} \geq 0 \\
& a_{i}^{f} \geq 0 \\
& \alpha_{i}=\frac{\alpha}{U_{i}^{\prime}\left(y_{i}\right)} \quad \text { with } \alpha=\left(\sum_{i} \frac{l_{i}}{U_{i}^{\prime}\left(y_{i}\right)}\right)^{-1} \\
& \chi_{i}=\left\{\begin{array}{l}
\alpha_{i} \quad \text { in status-quo mandates } \\
\beta_{i}=\frac{\beta}{U_{i}^{f \prime}\left(y_{i}^{f}\right)} \text { in adaptative mandates with } \beta=\left(\sum_{i} \frac{l_{i}^{f}}{U_{i}^{f \prime}\left(y_{i}^{f}\right)}\right)^{-1}
\end{array}\right.
\end{aligned}
$$

Let $\lambda, \mu, \xi_{\mathrm{i}}$ and $\psi_{\mathrm{i}}$ be the Lagrange multipliers attached to constraints (a2) to (a5). The Lagrangean of the problem is:

$$
\begin{aligned}
& \mathbf{L}=\sum_{i} \mathrm{l}_{\mathrm{i}} \alpha_{\mathrm{i}} \mathrm{U}_{\mathrm{i}}\left(\mathrm{y}_{\mathrm{i}}-\mathrm{a}_{\mathrm{i}}\right)+\varphi \sum_{\mathrm{i}} \mathrm{l}_{\mathrm{i}}^{\mathrm{f}} \chi_{\mathrm{i}} \mathrm{U}_{\mathrm{i}}^{\mathrm{f}}\left(\mathrm{y}_{\mathrm{i}}^{\mathrm{f}}-\mathrm{a}_{\mathrm{i}}^{\mathrm{f}}-\mathrm{d}_{\mathrm{i}}\left(\mathrm{x}^{+}+\mathrm{x}^{\mathrm{f}}\right), \mathrm{d}_{1}^{\mathrm{f}}, \ldots, \mathrm{d}_{\mathrm{i}-1}^{\mathrm{f}}, \mathrm{d}_{\mathrm{i}+1}^{\mathrm{f}}, \ldots, \mathrm{d}_{\mathrm{N}}^{\mathrm{f}}\right) \\
& \left.+\lambda \sum_{\mathrm{i}} \mathrm{l}_{\mathrm{i}} \mathrm{a}_{\mathrm{i}}-\mathrm{C}(\mathrm{x})\right]+\mu \varphi\left[\sum_{\mathrm{i}}^{\mathrm{f}} \mathrm{a}_{\mathrm{i}}^{\mathrm{f}}-\mathrm{C}^{\mathrm{f}}\left(\mathrm{x}^{\mathrm{f}}\right)\right]+\sum_{\mathrm{i}} \mathrm{l}_{\mathrm{i}} \xi_{\mathrm{i}} \mathrm{a}_{\mathrm{i}}+\varphi \sum_{i} \mathrm{l}_{\mathrm{i}}^{\mathrm{f}} \psi_{\mathrm{i}} \mathrm{a}_{\mathrm{i}}^{\mathrm{f}} \quad(\mathrm{a} 8)
\end{aligned}
$$

\section{Distribution of Abatement}

At optimum, derivation of $\mathbf{L}$ with regard to $\mathrm{a}_{\mathrm{i}}$ yields: 


$$
\frac{\partial \mathbf{L}}{\partial \mathrm{a}_{\mathrm{i}}}=0 \Leftrightarrow \alpha_{\mathrm{i}} U_{\mathrm{i}}^{\prime}\left(\mathrm{y}_{\mathrm{i}}-\mathrm{a}_{\mathrm{i}}\right)-\xi_{\mathrm{i}}=\lambda \quad \text { with }\left\{\begin{array}{l}
\xi_{\mathrm{i}}=0 \text { if } \mathrm{a}_{\mathrm{i}}>0 \\
\xi_{\mathrm{i}}>0 \text { if } \mathrm{a}_{\mathrm{i}}=0
\end{array}\right.
$$

Since weighted marginal utilities of consumption before abatement are equal (a6), there is a solution to (a9) where all $a_{i}$ are strictly positive, and corresponding Lagrange multipliers $\xi_{i}$ all equal to zero. Since second derivatives of all individual utility functions are negative, this solution is in fact the global maximum.

At optimum, derivation of $\mathbf{L}$ with regard to $a_{i}^{f}$ yields:

$$
\frac{\partial \mathbf{L}}{\partial a_{i}^{f}}=0 \Leftrightarrow \chi_{i} \frac{\partial U_{i}^{f}}{\partial c}\left(y_{i}^{f}-a_{i}^{f}-d_{i}\left(x+x^{f}\right), \ldots\right)-\psi_{i}=\mu \quad \text { with }\left\{\begin{array}{l}
\psi_{i}=0 \text { if } a_{i}^{f}+d_{i}>0 \\
\psi_{i}>0 \text { if } a_{i}^{f}+d_{i}=0
\end{array}\right.
$$

In adaptative mandates, weights $\chi_{i}$ are such that the vector $y_{i}^{f}$ is welfare maximizing. Provided residual damages are not too high in any country, there exists again a solution where all abatement expenditures $\mathrm{a}_{\mathrm{i}}^{\mathrm{f}}$ are positive, with Lagrange multipliers $\psi_{\mathrm{i}}$ equal to zero. On the other hand, if some residual damages are too high, then constraint (a5) becomes binding in these countries, and the corresponding abatement level $\mathrm{a}_{\mathrm{i}}^{\mathrm{f}}$ is zero.

In status-quo mandates, weights $\chi_{i}$ are not likely to be such that the vector $y_{i}^{f}$ is welfare maximizing. In that case, the optimal plan is to allocate abatement expenditures to the country which has the lowest weighted marginal utility of consumption before abatement, until optimal provision of public goods is reached, or until the second lowest weighted marginal utility level is reached, in which case both countries contribute, and so on. 


\section{Abatement Levels}

At optimum, derivation of $\mathbf{L}$ with regard to $x^{\mathrm{f}}$ yields:

$$
\begin{aligned}
& \frac{\partial \mathbf{L}}{\partial x^{f}}=0 \Leftrightarrow C^{f^{\prime}}\left(x^{f}\right)=-\sum_{i} 1_{i}^{f} \pi_{i} d_{i}^{\prime}\left(x+x^{f}\right)-\sum_{i} 1_{i}^{f} \pi_{i} \sum_{j \neq i} \frac{\partial U_{i}^{f}}{\partial c}\left(\frac{\partial U_{i}^{f}}{\partial d_{j}}\right)^{-1} d_{j}^{\prime}\left(x^{\prime}+x^{f}\right) \\
& \text { With } \pi_{i}=\frac{\chi_{i}}{\mu} \frac{\partial U_{i}^{f}}{\partial c}\left(y_{i}^{f}-a_{i}^{f}-d_{i}\left(x+x^{f}\right), \ldots\right)
\end{aligned}
$$

Weights $\pi_{\mathrm{i}}$ are ratios between the weighted marginal utility of consumption at optimum, and the shadow price of carbon $(\mu)$.

In adaptative mandates when none of the residual damages are too large, all weighted marginal utility of consumption are equal to the shadow price of carbon $\mu$. (a12) can be simplified in:

$$
C^{f^{\prime}}\left(x^{f}\right)=-\sum_{i} 1_{i}^{f} d_{i}^{\prime}\left(x+x^{f}\right)-\sum_{i} 1_{i}^{f} \sum_{j \neq i} \frac{\partial U_{i}^{f}}{\partial c}\left(\frac{\partial U_{i}^{f}}{\partial d_{j}}\right)^{-1} d_{j}^{\prime}\left(x+x^{f}\right)
$$

This is standard optimal provision of public goods: public goods should be provided up to the point where the last unit costs as much to produce as the marginal benefits it creates. The second term of the sum captures the fact that, in "universal" mandates, these benefits include avoiding damages abroad on top of at home.

If residual damages in some countries are too high, then (a10) states that the weighted marginal utility of consumption in these countries is higher than the shadow price of carbon $\mu$. For these countries, weights $\pi_{\mathrm{i}}$ are thus higher than unity.

The same occurs in status-quo mandates, but this time only a few countries have weights equal to one (those who contribute to abatement expenditures). All the others have weighted marginal utilities of abatement higher than the shadow price of carbon, and their weights $\pi_{\mathrm{i}}$ are also higher than one. The difference with the previous case is that most countries, a the few most impacted ones, are likely to be in this situation. 
Derivation of $\mathbf{L}$ with regard to first-period abatement level $x$ yields:

$$
\frac{\partial \mathbf{L}}{\partial \mathrm{x}}=0 \Leftrightarrow \lambda \mathrm{C}^{\prime}(\mathrm{x})=-\varphi \sum_{\mathrm{i}} 1_{\mathrm{i}}^{\mathrm{f}} \chi_{\mathrm{i}} \frac{\partial \mathrm{U}_{\mathrm{i}}^{\mathrm{f}}}{\partial \mathrm{c}} \mathrm{d}_{\mathrm{i}}^{\prime}\left(\mathrm{x}+\mathrm{x}^{\mathrm{f}}\right)-\varphi \sum_{\mathrm{i}} 1_{\mathrm{i}}^{\mathrm{f}} \chi_{\mathrm{i}} \sum_{\mathrm{j} \neq \mathrm{i}} \frac{\partial \mathrm{U}_{\mathrm{i}}^{\mathrm{f}}}{\partial \mathrm{d}_{\mathrm{j}}} \mathrm{d}_{\mathrm{i}}^{\prime}\left(\mathrm{x}+\mathrm{x}^{\mathrm{f}}\right)
$$

Since Lagrange multiplier $\lambda$ is equal to the weighted marginal utility of consumption at first period (a9), this equation can be written:

$$
\begin{aligned}
& C^{\prime}(x)=-\varphi \sum_{i} 1_{i}^{f} \omega_{i} \frac{U_{i}^{f}\left(y_{i}^{f}-a_{i}^{f}-d_{i}\left(x+x^{f}\right)\right)}{U_{i}^{\prime}\left(y_{i}-a_{i}\right)} d_{i}^{\prime}\left(x+x^{f}\right) \\
& -\varphi \sum_{i} 1_{i}^{f} \omega_{i} \sum_{j \neq i} \frac{\partial U_{i}^{f} / \partial d_{j}}{U_{i}^{f}\left(y_{i}^{f}-a_{i}^{f}-d_{i}^{f}\right)} d_{j}^{\prime}\left(x+x^{f}\right) \\
& \text { Where } \omega_{i}=\frac{\chi_{i}}{\alpha_{i}}
\end{aligned}
$$

Marginal abatement costs at first period take the general form of a discounted sum of future marginal benefits of abatement. The value of the discount factors, however, depends on the mandate.

In status-quo mandates, coefficients $\omega_{\mathrm{i}}$ are equal to one. The discount factors become $\varphi \frac{U_{i}^{f}\left(y_{i}^{f}-a_{i}^{f}-d_{i}\left(x+x^{f}\right)\right)}{U_{i}^{\prime}\left(y_{i}-a_{i}\right)}$, which are exactly country-level consumption discount factors at the margin of the (post abatement) growth path. The discount factors are thus likely to be lower for countries with higher growth rates, thereby reducing the weight attached to their damages in (a15).

In adaptative mandates, on the other hand, the discount factors becomes $\varphi \frac{\beta}{\alpha} \frac{U_{i}^{\prime}\left(y_{i}\right)}{U_{i}^{f \prime}\left(y_{i}^{f}\right)} \frac{U_{i}^{f \prime}\left(y_{i}^{f}-a_{i}^{f}-d_{i}\left(x+x^{f}\right)\right)}{U_{i}^{\prime}\left(y_{i}-a_{i}\right)}$. If abatement expenses and residual damages remain small with regard to baseline revenues, then the last two terms cancel out, and all discount factors are roughly equal to a common value $\varphi \frac{\beta}{\alpha^{\prime}}$ which can be interpreted as a population-weighted average discount factor amongst countries. 


\section{Appendix 2: Domain of Validity of Property (12)}

Let $U$ be a twice differentiable utility function defined over $\mathbb{R}^{+}$, with $U^{\prime}>0$ and $U^{\prime \prime}<0$. We are looking for the conditions under which the following property is valid:

(P1) For all $x>0$ and all $y>0, x<y \Rightarrow \frac{U^{\prime \prime}(x)}{U^{\prime}(x)}<\frac{U^{\prime \prime}(y)}{U^{\prime}(y)}$

For property $\mathbf{P 1}$ to hold, $\mathrm{U}^{\prime}$ must be sufficiently convex. ${ }^{23}$ We show here that if $U^{\prime \prime} / U^{\prime}$ is monotonous, and if $U$ is unbounded, then P1 holds.

Proof: Let us assume $U$ unbounded. If $U^{\prime \prime} / U^{\prime}$ were decreasing, then we would have $\left(U^{\prime \prime} / U^{\prime}\right)^{\prime}=\left[\ln \left(U^{\prime}\right)\right]^{\prime \prime} \leq 0$ over $[1,+\infty[$.

Let $G$ be the twice differentiable function such that $G(1)=U^{\prime}(1)$, $[\ln (G)]^{\prime}(1)=\left[\ln \left(U^{\prime}\right)\right]^{\prime}(1)$, and $[\ln (G)]^{\prime}$ constant over $[1,+\infty[$. G exists, and is uniquely defined. Precisely, $G(c)=e^{a c+b}$ with $a+b=U^{\prime}(1)$ and $a=$ $\left[\ln \left(\mathrm{U}^{\prime}\right)\right]^{\prime}(1)<0$.

Since $G(1)=U^{\prime}(1),[\ln (G)]^{\prime}(1)=\left[\ln \left(U^{\prime}\right)\right]^{\prime}(1)$, and $\left[\ln \left(U^{\prime}\right)\right]^{\prime \prime} \leq 0$ while $[\ln (G)]^{\prime \prime}=0$, we have $U^{\prime}(c) \leq G(c)$ for all $c$ in $[1,+\infty[$.

$\mathrm{C}$

$\mathrm{C}$

But $\int G(x) d x$ is bounded, and thus so is $\int U^{\prime}(x) d x$, which 1

1

contradicts the initial assumption that $\mathrm{U}$ is not bounded. C.Q.F.D.

\section{Appendix 3: Model Resolution under Uncertainty}

To model uncertainty, we assume the planner faces a finite set of possible scenarios indexed by $\mathrm{j} \in\{1,2, \ldots, \mathrm{M}\}$. Each set is characterized by climate change impacts $\mathrm{d}_{\mathrm{ij}}$, second-period baseline income $\mathrm{y}_{\mathrm{ij}}^{\mathrm{f}}$, and future abatement costs $C_{j}^{f}$. The planner also knows that full information about the true state of the world will be revealed at the

\footnotetext{
${ }^{23}$ In the literature on attitudes towards risk, $\mathbf{P 1}$ is equivalent to decreasing absolute risk aversion.
} 
beginning of second period. But at the beginning of the first period, the planner only has a set of subjective probabilities $p_{j}$ attached to each possible future state of the world. Assuming the planner's utility function is Von-Neumann, the optimization problem becomes:

$$
\begin{aligned}
& \operatorname{Max} \sum_{i} 1_{i} \alpha_{i} U_{i}\left(y_{i}-a_{i}\right) \\
& +\sum_{j} p_{j} \varphi \sum_{i} 1_{i}^{f} \beta_{i j} U_{i}^{f}\left(y_{i j}^{f}-a_{i j}^{f}-d_{i j}\left(x+x_{j}^{f}\right), d_{1 j}^{f}, \ldots, d_{i-1}^{f}, d_{i+1}^{f}, \ldots, d_{N j}^{f}\right) \\
& \sum_{i} 1_{i} a_{i}=C(x) \\
& \sum_{i} 1_{i}^{f} a_{i j}^{f}=C_{j}^{f}\left(x_{j}^{f}\right) \\
& a_{i} \geq 0 \\
& a_{i j}^{f} \geq 0 \\
& \alpha_{i}=\frac{\alpha}{U_{i}^{\prime}\left(y_{i}\right)} \quad \text { with } \alpha=\left(\sum_{i} \frac{l_{i}}{U_{i}^{\prime}\left(y_{i}\right)}\right)^{-1} \\
& \beta_{i j}=\left\{\begin{array}{c}
\alpha_{i} \quad \text { in status-quo mandates } \\
\beta_{j}^{f} \\
U_{i}^{f}\left(y_{i j}^{f}\right)
\end{array} \text { in adaptative mandates } \quad \text { with } \beta_{j}=\left(\sum_{i} \frac{1}{U_{i}^{\prime}\left(y_{i j}^{f}\right)}\right)^{-1}\right.
\end{aligned}
$$

The Lagrangean becomes

$$
\begin{aligned}
& \mathbf{L}=\sum_{i} 1_{i} \alpha_{i} U_{i}\left(y_{i}-a_{i}\right)+\varphi \sum_{i j} 1_{i}^{f} p_{j} \beta_{i j} U_{i}^{f}\left(y_{i j}^{f}-a_{i j}^{f}-d_{i j}\left(x+x_{j}^{f}\right), d_{1 j}^{f}, \ldots, d_{i-1}^{f}, d_{i+1 j}^{f}\right. \\
& \left., \ldots, d_{N j}^{f}\right)+\lambda\left[\sum_{i}^{f} 1_{i} a_{i}-C(x)\right]+\sum_{j} p_{j} \mu_{j} \varphi\left[\sum_{i} 1_{i}^{f} a_{i j}^{f}-C_{j}^{f}\left(x_{j}^{f}\right)\right]+\sum_{i} 1_{i} \xi_{i} a_{i} \\
& +\varphi \sum_{i j} 1_{i}^{f} \psi_{i j} a_{i j}^{f}
\end{aligned}
$$

And first-order conditions are now

$$
\frac{\partial \mathbf{L}}{\partial \mathrm{a}_{\mathrm{i}}}=0 \Leftrightarrow \alpha_{\mathrm{i}} \mathrm{U}_{\mathrm{i}}^{\prime}\left(\mathrm{y}_{\mathrm{i}}-\mathrm{a}_{\mathrm{i}}\right)-\xi_{\mathrm{i}}=\lambda
$$




$$
\begin{gathered}
\frac{\partial \mathbf{L}}{\partial \mathrm{a}_{\mathrm{ij}}^{\mathrm{f}}}=0 \Leftrightarrow \beta_{\mathrm{ij}} \frac{\partial \mathrm{U}_{\mathrm{i}}^{\mathrm{f}}}{\partial \mathrm{c}}\left(\mathrm{y}_{\mathrm{ij}}^{\mathrm{f}}-\mathrm{a}_{\mathrm{ij}}^{\mathrm{f}}-\mathrm{d}_{\mathrm{ij}}\left(\mathrm{x}+\mathrm{x}_{\mathrm{j}}^{\mathrm{f}}\right), \ldots\right)-\psi_{\mathrm{ij}}=\mu_{\mathrm{j}} \\
\frac{\partial \mathbf{L}}{\partial \mathrm{x}_{\mathrm{j}}^{\mathrm{f}}}=0 \Leftrightarrow \mu_{\mathrm{j}} \mathrm{C}_{\mathrm{j}}^{\mathrm{fl}}\left(\mathrm{x}_{\mathrm{j}}^{\mathrm{f}}\right)=-\sum_{\mathrm{i}} \mathrm{l}_{\mathrm{i}}^{\mathrm{f}} \beta_{\mathrm{ij}} \frac{\partial \mathrm{U}_{\mathrm{i}}^{\mathrm{f}}}{\partial \mathrm{c}} \mathrm{d}_{\mathrm{ij}}^{\mathrm{ij}}\left(\mathrm{x}+\mathrm{x}_{\mathrm{j}}^{\mathrm{f}}\right)-\sum_{\mathrm{i}} \mathrm{l}_{\mathrm{i}}^{\mathrm{f}} \beta_{\mathrm{ij}} \sum_{\mathrm{k} \neq \mathrm{i}} \frac{\partial \mathrm{U}_{\mathrm{k}}^{\mathrm{f}}}{\partial \mathrm{d}_{\mathrm{kj}}} \mathrm{d}_{\mathrm{kj}}^{\mathrm{f}}\left(\mathrm{x}+\mathrm{x}_{\mathrm{j}}^{\mathrm{f}}\right) \\
\frac{\partial \mathbf{L}}{\partial \mathrm{x}}=0 \Leftrightarrow \lambda \mathrm{C}^{\prime}(\mathrm{x})=-\sum_{\mathrm{j}} \mathrm{p}_{\mathrm{j}} \varphi \sum_{\mathrm{i}} \mathrm{l}_{\mathrm{i}}^{\mathrm{f}} \beta_{\mathrm{ij}} \frac{\partial \mathrm{U}_{\mathrm{i}}^{\mathrm{f}}}{\partial \mathrm{c}} \mathrm{d}_{\mathrm{ij}}^{\prime}\left(\mathrm{x}+\mathrm{x}_{\mathrm{j}}^{\mathrm{f}}\right) \\
-\sum_{\mathrm{j}} \mathrm{p}_{\mathrm{j}} \varphi \sum_{\mathrm{i}} \mathrm{l}_{\mathrm{i}}^{\mathrm{f}} \beta_{\mathrm{ij}} \sum_{\mathrm{k} \neq \mathrm{i}} \frac{\partial \mathrm{U}_{\mathrm{k}}^{\mathrm{f}}}{\partial \mathrm{d}_{\mathrm{kj}}} \mathrm{d}_{\mathrm{kj}}^{\prime}\left(\mathrm{x}+\mathrm{x}_{\mathrm{j}}^{\mathrm{f}}\right)
\end{gathered}
$$

\section{Appendix 4: Numerical Illustration}

We consider two regions, called "North" and "South" respectively. "North" comprises high-income countries, as per World Bank (2002) definition, and "South" low and middle income ones. First period is 2000-2050, and second period 2050-2100. First-period income and population data are given by World Bank (2002). ${ }^{24}$ In the baseline scenario, economic growth in the North is assumed to be $2.5 \%$ per year, against $3 \%$ in the South. World population is assumed to grow by 2 billions people, all of them in the developing world. Table 4 summarizes key parameters of the baseline scenario.

Without action, carbon dioxide emissions are assumed to reach $513 \mathrm{GtCO}_{2}$ during the first period, and $688 \mathrm{GtCO}_{2}$ during the second one, as in the IPCC IS92a scenario.

Abatement costs at first and second period are assumed quadratic with respect to total abatement expenditures. We assume that marginal costs of a zero-carbon economy is $\$ 1,500 / \mathrm{tC}$ during the first period, dropping to $\$ 1,000 / \mathrm{tC}$ during the second period. The abatement cost functions thus become:

\footnotetext{
${ }^{24}$ For simplicity's sake, we use 2000 and 2050 data respectively as averages for the two periods.
} 


$$
\begin{aligned}
& x=513\left(1-2.89 \sqrt{\frac{l_{n} a_{n}+l_{s} a_{s}}{l_{n} y_{n}+l_{s} y_{s}}}\right) \\
& x^{f}=688\left(1-5.91 \sqrt{\frac{1_{n}^{f} a_{n}^{f}+1_{s}^{f} a_{s}^{f}}{l_{n}^{f} y_{n}^{f}+1_{s}^{f} y_{s}^{f}}}\right)
\end{aligned}
$$

Damages are assumed to be cubic with the total amount of carbon emitted in the atmosphere $x+x^{f}$.

$$
d_{i}^{f}\left(x+x^{f}\right)=\theta_{i}\left(\frac{x+x^{f}}{1200}\right)^{3}
$$

We will use several values for coefficients $\theta$.

All utility functions are assumed to be logarithmic in consumption. The utility discount rate is set at $1 \%$ per year.

\section{Appendix 5: Proof of Property in Section 4.1}

Let $U$ be a twice differentiable utility function defined over $\mathbb{R}^{+}$, with $U^{\prime}>0$ and $U^{\prime \prime}<0$. Let $c_{1}, \ldots, c_{n}, r_{1}, \ldots, r_{n}$ be strictly positive real numbers with $r_{1}>r_{i}$ for all $i \geq 2$. We want to explore under which conditions the following holds:

$$
\text { (P2) } \frac{U^{\prime}\left(r_{1} c_{1}\right)}{U^{\prime}\left(c_{1}\right)}<\frac{U^{\prime}\left(r_{i} c_{i}\right)}{U^{\prime}\left(c_{i}\right)} \text { for all } i \geq 2
$$

We give two partial answers to that question. First, let us note that (P2) holds for all utility functions such that $U^{\prime}(r c)=r^{-k} U^{\prime}(c)(k>0)$. Those include, in particular, classical utility functions such as $\ln (\mathrm{c})$, and $\mathrm{c}^{\mathrm{a}}$ with $0<\mathrm{a}<1$.

Second, when growth rates $r$ are small, we have:

$$
\frac{\mathrm{U}^{\prime}(\mathrm{c}(1+\mathrm{g}))}{\mathrm{U}^{\prime}(\mathrm{c})} \approx \frac{\mathrm{U}^{\prime}(\mathrm{c})+\mathrm{U}^{\prime \prime}(\mathrm{c}) \mathrm{gc}}{\mathrm{U}^{\prime}(\mathrm{c})}=1+\frac{\mathrm{U}^{\prime \prime}(\mathrm{c})}{\mathrm{U}^{\prime}(\mathrm{c})} \mathrm{cg}
$$

And thus:

$$
\frac{\mathrm{U}^{\prime}\left(\mathrm{c}_{1}\left(1+\mathrm{g}_{1}\right)\right)}{\mathrm{U}^{\prime}\left(\mathrm{c}_{1}\right)}<\frac{\mathrm{U}^{\prime}\left(\mathrm{c}_{2}\left(1+\mathrm{g}_{2}\right)\right)}{\mathrm{U}^{\prime}\left(\mathrm{c}_{2}\right)} \quad \text { i.i.f }-\frac{\mathrm{U}^{\prime \prime}\left(\mathrm{c}_{1}\right)}{\mathrm{U}^{\prime}\left(\mathrm{c}_{1}\right)} \mathrm{c}_{1} \mathrm{~g}_{1}>-\frac{\mathrm{U}^{\prime \prime}\left(\mathrm{c}_{2}\right)}{\mathrm{U}^{\prime}\left(\mathrm{c}_{2}\right)} \mathrm{c}_{2} \mathrm{~g}_{2}
$$


(P2) thus holds - locally at least-if -c U'/U' is constant. The result is less clear otherwise. When -c $U^{\prime \prime} / U^{\prime}$ is decreasing with consumption, then $(\mathbf{P 2})$ remains valid if the country which grows at the fastest rate is also the country with lowest initial wealth level $\left(c_{1}<c_{2}, g_{1}>g_{2}\right)$. When $-c U^{\prime \prime} / U^{\prime}$ is increasing with consumption, then the result is ambiguous. $^{25}$

${ }^{25}$ In the literature on attitudes towards risk, $-\mathrm{c} \mathrm{U}^{\prime \prime} / \mathrm{U}^{\prime}$ is the relative risk aversion. The property holds for constant relative risk aversion, and decreasing risk aversion functions. It is ambiguous for increasing risk aversion ones. 


\section{References}

Agarwal, A., Narain, S., 1991. Global Warming in an Unequal World, a case of environmental colonialism. Center for Science and Environment, Delhi.

Azar, C., 1999. Weight factors in cost-benefit analysis of climate change. Environmental and Resource Economics 13(3), 249-268.

Bodansky, D., 2001. Bonn Voyage. Kyoto's Uncertain Revival. The National Interest, Fall, 45-55.

Bruce, J., Lee, H., Haites, E. (eds.), 1996. Climate Change 1995: Economic and Social Dimensions of Climate Change. Cambridge University Press, Cambridge.

Chao, H.-P., Peck, S., 2000. Greenhouse gas abatement: how much? and who pays? Resource and Energy Economics 22(1), 1-20.

Chichilnisky, G., Heal, G., Starrett, D., 2000. Equity and efficiency in environmental markets: global trade in carbon emissions. In Chichilnisky, G., Heal, G. (eds.). Environmental markets, Colombia University Press, pp.46-67.

Grubb, M., Vrolijk, C., Brack, D., 1999. The Kyoto protocol, a guide and an assessment, Royal Institute of International Affairs, London.

Guesnerie, R., 1995. The genealogy of modern theoretical public economics: from first best to second best. European Economic Review 39(3/4), 353-381.

Hourcade, J.-C., 1994. Economic issues and negotiation on global environment: some lessons from the recent experience on greenhouse effect. In Carraro C. (Ed.) Trade Innovation and Environment. Klüwer Academics Publishers, Dordrecht, pp.385-405.

Hourcade, J.-C., 2000. Le climat au risque de la négociation internationale. Le Débat.

Hourcade, J.-C., Richels, R., Robinson, J., 1996. Estimating the costs of mitigating greenhouse gases. In Bruce, J., Lee, H., and Haites, E. (eds.). Climate Change 1995: Economic and Social Dimensions of Climate Change. Cambridge University Press, Cambridge, pp.263-296. 
Lecocq, F., Crassous, R., 2003. International Climate Regime beyond 2012: Are Quota Allocation Rules Robust to Uncertainty? Policy Research Working Paper 3000. World Bank, Washington DC.

McCarthy, J.J., Canziani ,O.F., Leary, N.A., Dokken, D.J., White, K.S. (Eds), 2001. Climate Change 2001: Impacts, Adaptation and Vulnerability. Cambridge University Press, Cambridge.

Naki enovi , N., Swart, R. (Eds), 2000. Special Report of the Intergovernmental Panel on Climate Change on emission scenarios. Cambridge University Press, Cambridge.

Negishi, T., 1960. Welfare economics and existence of an equilibrium for a competitive economy. Metroeconomica 12, 92-97.

Nordhaus, W.D., Yang, Z. A Regional Dynamic General-Equilibrium Model of Alternative Climate-Change Strategies. American Economic Review 86(4), 741-765.

OECD, 1993. International economic instruments and climate change. OECD, Paris.

Rawls. J., 1971. A theory of justice. The Belknap Press of Harvard University Press, Cambridge.

Sandler, T., Smith, K.V., 1976. Intertemporal and intergenerational Pareto efficiency. Journal of Environmental Economics and Management 2, 151-159.

Schelling, T., 1995. Intergenerational discounting. Energy Policy 23(4/5), 395-401.

Sen, A. K., 1987. On ethics and economics. Basil Blackwell Publishers, Oxford.

Toth, F., Mwandosya, M., et alii, 2001. Decision-making Frameworks. In Metz, B., Davidson, O., Swart, R., Pan, J. (Eds.). Climate Change 2001: Mitigation, Contribution of Working Group III to the Third Assessment Report to the IPCC. Cambridge University Press, Cambridge, pp.601-690.

World Bank, 2002. World Development Indicators. Washington DC. World Bank, 2003. Global Economic Prospects, Washington DC. 
Table 1: Second-Period Expenditures in Adaptative - Dynastic Mandates

\begin{tabular}{|c|c|c|c|c|c||c|c|c|}
\hline \multicolumn{3}{|c|}{ Scenario } & \multicolumn{6}{c|}{ Optimal Mitigation Policy } \\
\hline & $\begin{array}{c}\text { Damage } \\
\text { maximum } \\
\text { North }\end{array}$ & $\begin{array}{c}\text { Damage } \\
\text { maximum } \\
\text { South }\end{array}$ & $\begin{array}{c}\text { Abatement } \\
\text { Expenditures } \\
\mathrm{N}\left(\mathrm{a}_{\mathrm{N}}\right)\end{array}$ & $\begin{array}{c}\text { Residual } \\
\text { Damages } \\
\mathrm{N}\left(\mathrm{d}_{\mathrm{N}}\right)\end{array}$ & $\begin{array}{c}\text { Total } \\
\text { climate } \\
\text { bill N } \\
\left(\mathrm{a}_{\mathrm{N}}+\mathrm{d}_{\mathrm{N}}\right)\end{array}$ & $\begin{array}{c}\text { Abatement } \\
\text { Expenditures } \\
\mathrm{S}\left(\mathrm{a}_{\mathrm{S}}\right)\end{array}$ & $\begin{array}{c}\text { Residual } \\
\text { Damages } \\
\mathrm{S}\left(\mathrm{d}_{\mathrm{s}}\right)\end{array}$ & $\begin{array}{c}\text { Total } \\
\text { climate } \\
\text { bill S } \\
\left(\mathrm{as}_{\mathrm{S}}+\mathrm{d}_{\mathrm{s}}\right)\end{array}$ \\
\hline $\mathrm{a}$ & $5 \%$ & $5 \%$ & $1.01 \%$ & $1.24 \%$ & $2.25 \%$ & $1.01 \%$ & $1.24 \%$ & $2.25 \%$ \\
\hline $\mathrm{b}$ & $4 \%$ & $6 \%$ & $1.09 \%$ & $1.06 \%$ & $2.15 \%$ & $0.55 \%$ & $1.60 \%$ & $2.15 \%$ \\
\hline $\mathrm{c}$ & $3 \%$ & $7 \%$ & $1.18 \%$ & $0.86 \%$ & $2.04 \%$ & $0.04 \%$ & $2.00 \%$ & $2.04 \%$ \\
\hline $\mathrm{d}$ & $2 \%$ & $8 \%$ & $1.09 \%$ & $0.61 \%$ & $1.70 \%$ & $0 \%$ & $2.47 \%$ & $2.47 \%$ \\
\hline
\end{tabular}

All figures are percentage of second period income $y$.

Source: Authors' calculation. See Appendix 4 for calibration details. 
Table 2: Total Abatement Level in Adaptative Dynastic Mandate

\begin{tabular}{|c|c|c|c|c|c|}
\hline \multicolumn{3}{|c|}{ Scenario } & \multicolumn{3}{|c|}{ Optimal Mitigation Policy } \\
\hline & $\begin{array}{c}\text { Damage } \\
\text { maximum } \mathrm{N}\end{array}$ & $\begin{array}{c}\text { Damage } \\
\text { maximum S }\end{array}$ & 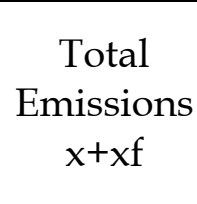 & $\begin{array}{c}\text { Second- } \\
\text { Period } \\
\text { Climate bill } \\
\text { N }\end{array}$ & $\begin{array}{l}\text { Second- } \\
\text { Period } \\
\text { Climate bill } \\
\text { S }\end{array}$ \\
\hline $\mathrm{a}$ & $5.0 \%$ & $5.0 \%$ & 754 & $2.25 \%$ & $2.25 \%$ \\
\hline $\mathrm{b}$ & $4.5 \%$ & $6.2 \%$ & 754 & $2.25 \%$ & $2.25 \%$ \\
\hline C & $4.0 \%$ & $7.4 \%$ & 754 & $2.25 \%$ & $2.25 \%$ \\
\hline $\mathrm{d}$ & $3.5 \%$ & $8.6 \%$ & 754 & $2.25 \%$ & $2.25 \%$ \\
\hline $\mathrm{e}$ & $3 \%$ & $9.8 \%$ & 754 & $2.17 \%$ & $2.44 \%$ \\
\hline $\mathrm{f}$ & $2 \%$ & $12.2 \%$ & 753 & $1.93 \%$ & $3.02 \%$ \\
\hline $\mathrm{g}$ & $1 \%$ & $14.7 \%$ & 751 & $1.69 \%$ & $3.59 \%$ \\
\hline $\mathrm{h}$ & $0.5 \%$ & $15.9 \%$ & 750 & $1.58 \%$ & $3.87 \%$ \\
\hline j & $0.0 \%$ & $17.1 \%$ & 749 & $1.46 \%$ & $4.15 \%$ \\
\hline
\end{tabular}

In all scenarios, the aggregate damage function is the same. All figures are percentage of second period income $y f$.

Source: Authors' calculation. See Appendix 4 for calibration details. 
Table 3: Optimal Emission Levels in All Mandates (First Period, Second Period)

\begin{tabular}{|c|c|c|}
\hline $\begin{array}{l}\text { Solidarity } \\
\text { with future generations }\end{array}$ & Status-Quo & Adaptative \\
\hline Dynastic & $(488,358)$ & $(484,380)$ \\
\hline Universal & $(482,282)$ & $(477,310)$ \\
\hline
\end{tabular}

Source: Authors' calculation. Baseline emissions $(513,688)$, damages up to $2 \%$ of revenues in $N$, against $5 \%$ of GDP in $S$, universal utility functions of the form $U=\ln (c)\left(1-0.01 \frac{d_{s}+d_{n}}{d_{s}^{m a x}+d_{n}^{\max }}\right)$ all other assumptions in Appendix 4. 
Table 4: Economic and Population Assumptions

\begin{tabular}{|l|l|l|l|c|}
\hline & \multicolumn{2}{|c|}{ First Period (2000) } & \multicolumn{2}{c|}{ Second Period (2050) } \\
\hline & $\mathrm{l}_{\mathrm{i}}$ (billions) & $\mathrm{y}_{\mathrm{i}}(1995 \mathrm{US} \$)$ & $\mathrm{l}_{\mathrm{i}}^{\mathrm{f}}$ (billions) & $\mathrm{y}_{\mathrm{i}}^{\mathrm{f}}(1995$ US\$) \\
\hline North & 0.95 & 26,750 & 0.95 & 91,943 \\
\hline South & 5.11 & 1,160 & 7.11 & 5,085 \\
\hline
\end{tabular}


Figure 1: Optimal abatement levels at first period for two regions differing only by income

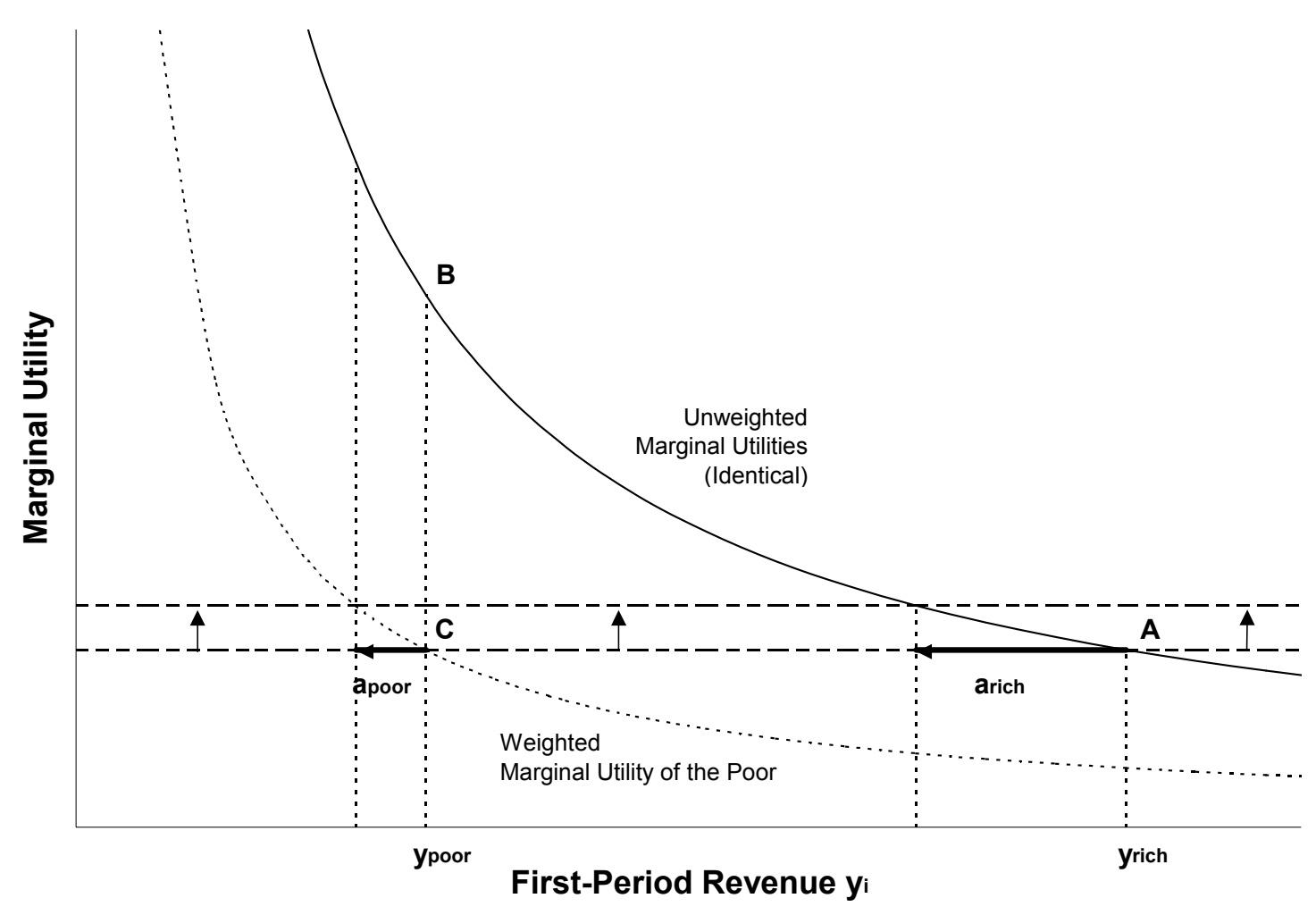


Figure 2: Optimal abatement levels at second period for two regions differing only by income

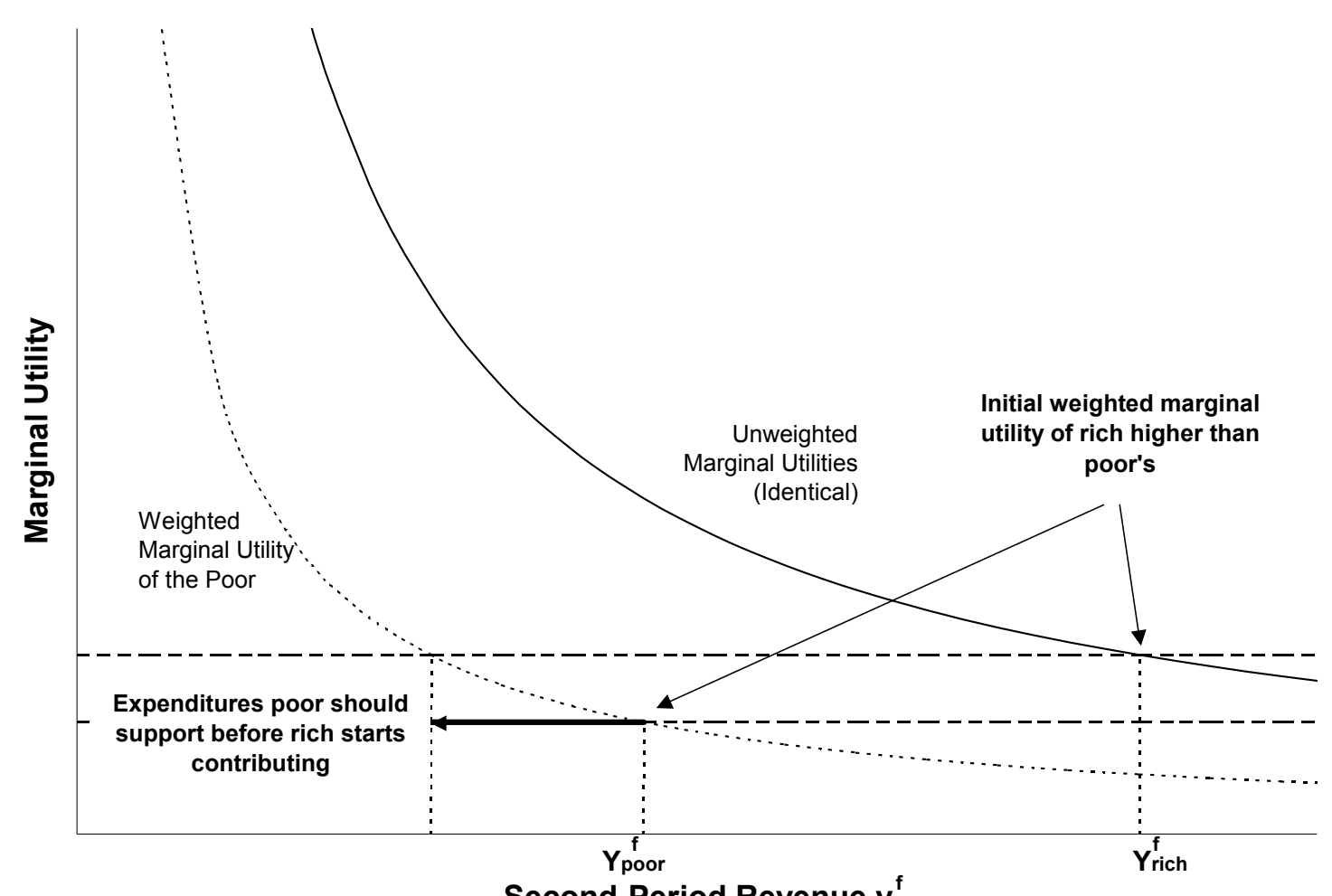

Second-Period Revenue $y_{i}^{f}$ 